\title{
La erradicación de la fiebre amarilla en Mérida, Yucatán: una historia de tenacidad y éxito.
}

\author{
Historia de la Medicina
}

Renán A. Góngora-Biachi.

Laboratorio de Hematología, Centro de Investigaciones Regionales, “Dr. Hideyo Noguchi”, Universidad Autónoma de Yucatán, Mérida, Yucatán.

\section{RESUMEN.}

La fiebre amarilla es un síndrome de fiebre hemorrágica ocasionada por un flavivirus, el virus de la fiebre amarilla, y que es transmitido por los mosquitos Aëdes aegypti y Haemagogus. El Popol$V u h$, libro sagrado de los mayas quichés, relata que la fiebre amarilla entre los mayas se debe a la constante convivencia con los monos y relata la epidemia de una enfermedad llamada xekik (vómito de sangre) ocurrida entre los años de 1480 a 1485. Otros textos sagrados, como el Chilam Balam de Chumayel, Tizimín y Kaua, también describen las epidemias de xekik. Fray Diego de Landa refiere que la primera epidemia en la región ocurrió aproximadamente en 1483-84. Descrita como la "peste", hubo epidemias de fiebre amarilla en 1569, y 1571-1572. Otras Epidemias de fiebre amarilla ocurrieron en 1648-1650 y en 1699. La fiebre amarilla en Yucatán ya era endémica. Sin embargo tuvo que afrontar cuatro brotes epidémicos más en 1699, en 1715, en 1730 y en 1744. El Yucatán del siglo XIX y de principios del siglo XX, tampoco se libraría de esta enfermedad. De 1825 a 1830 se reportaron incremento en el número de casos de Yucatán y para 1858 se consideraba endémicamente importante en Yucatán. En 1905 y 1906, y posteriormente en 1911, hubo nuevos brotes epidémicos de fiebre amarilla, principalmente en Mérida. Se describe la campaña de control del Aëdes aegypti y en consecuencia de la fiebre amarilla, acontecida en Mérida Yucatán, de 1921 a 1923, bajo la dirección del Dr. Diego Hernández Fajardo.

(Rev Biomed 2004; 15:251- 258)

Palabras clave: fiebre amarilla, epidemias, Yucatán México, Historia de la Medicina.

\section{SUMMARY.}

Erradication of the yellow fever in Merida, Yucatán: tenacity and success history.

The yellow fever is a haemorragic fever sindrome caused by a flavivirus, the yellow fever virus, which is transmitted by the Aëdes aegypti and Haemagogus mosquitoes. The Popol-Vuh, the sacred book of the mayan indians, relates how yellow fever among the mayans was due to their living in close proximity to

Solicitud de sobretiros: M.C. Renán A. Góngora-Biachi, Centro de Investigaciones Regionales "Dr. Hideyo Noguchi”, Ave. Itzáes $N^{o} 490$ por 59, C.P. 97000, Mérida, Yucatán, México. Correo electrónico: gbiachi@tunku.uady.mx Recibido el 15/Octubre/2004. Aceptado para publicación el 25/Noviembre/2004. 


\section{RA Góngora-Biachi.}

monkeys and tels of a sickness called "xekik" (vomiting blood) which ocurred between 1480 and 1485. Other sacred texts such as the Chilam Balam of Chumayel, Tizimin and Kaua,also described the epidemics of "xekik". Fray Diego de Landa refers to the first epidemic in the region which ocurred aproximately from 1483 to 1484 . There were epidemics of yellow fever in 1569 and 1571-1572, described as the "peste". Other epidemics of yellow fever ocurred in 1648-1650, in 1699, in 1715, 1730, and 1744 . The Yucatan of the $19^{\text {th }}$ century and the first years of the $20^{\text {th }}$ century the yellow fever was present, in similar form of the others cneturies, like an endemic disease. From 1825 to 1830 there was increment in the cases. In 1905-1906and 1911, there were new epidemic events. This paper described the erradication campaign against the yellow fever through the control of the vector aëdes aegypti mosquito, who was conducted by Dr. Diego Hernandez-Fajardo, in Merida, Yucatan, Mexico from 1921 to 1923.

(Rev Biomed 2004; 15:251- 258)

Key words: yellow fever, epidemics, Yucatan Mexico, History of Medicine.

\section{INTRODUCCIÓN.}

La fiebre amarilla es un síndrome de fiebre hemorrágica ocasionada por un flavivirus, el virus de la fiebre amarilla, y que es transmitido por los mosquitos Aëdes aegypti y Haemagogus (1). El virus de la fiebre amarilla ha causado epidemias importantes en el continente americano, África y Europa. El periodo de incubación de este virus es de 3 a 6 días, ocasiona una mortalidad de $20 \%$, no tiene preferencia por edades ni por género. Posterior al periodo de incubación la enfermedad se manifiesta por ictericia, hemorragias, vómitos negros, anuria y delirio final, ocasionado por la necrosis hepática que ocasiona esta fiebre hemorrágica (1). Desde marzo de 1923 y hasta la fecha se considera erradica de México (2).

El virus de la fiebre amarilla tiene un ciclo selvático y un ciclo urbano. En el ciclo selvático participan los monos y los mosquitos Aëdes en África y los mosquitos Haemagogus en las selvas tropicales americanas. Aunque en la época precolombina ya se describían casos de fiebre amarilla en América, debe atribuirse estos casos al ciclo selvático y las epidemias ocasionadas durante el periodo de la conquista europea y la época colonial se atribuyen a la importación al nuevo mundo del A. Aegypti, vector que ha sido el causante de los brotes urbanos (3).

\section{LA FIEBRE AMARILLA EN LA ÉPOCA PRECOLOMBINA, DURANTE LA COLONIA Y EL MÉXICO INDEPENDIENTE (4).}

El Popol-Vuh, libro sagrado de los mayas quichés, relata que la fiebre amarilla entre los mayas se debe a la constante convivencia con los monos y relata la epidemia de una enfermedad llamada xekik (vómito de sangre) ocurrida entre los años de 1480 a 1485. Otros textos sagrados de los mayas de Yucatán, México, como el Chilam Balam de Chumayel, Tizimín y Kaua también describen las epidemias de xekik (5).

Fray Diego de Landa, en su obra Relación de las Cosas de Yucatán, escrita en 1560, refiere que la primera epidemia en la región ocurrió aproximadamente en 1483-84 (6). Descrita como la "peste", hubo epidemias de fiebre amarilla en 1569 , y 1571-1572. El impacto de estas epidemias, aunado otras patologías importadas por los europeos (viruela, sarampión y "tabardillo" (tifus exantemático) ) y la hambruna por plagas y sequías, fue tal que para 1572 se estimaba que un tercio de la población indígena había sucumbido. Otras Epidemias de fiebre amarilla ocurrieron en 1648-1650 y en 1699 (7).

El brote epidémico de la fiebre amarilla de 1648 ha sido uno de los mejores descritos por actores de la época. Fray Diego López Cogolludo en su "Historia de Yucatán” escrita en 1688 (8). La epidemia predominó en la región por un lapso de dos años y su efecto fue tan desbastador la actividad milpera se colapsó que en 1650 hubo hambruna y las comunidades fueron despobladas al huir los mayas a las zonas selváticas o a la costa.

La fiebre amarilla en Yucatán ya era endémica. Sin embargo tuvo que afrontar cuatro brotes epidémicos más en 1699, en 1715, en 1730 y en 1744 (3). Y así la fiebre amarilla persistiría hasta el

\section{Revista Biomédica}




\section{Erradicación de la fiebre amarilla en Yucatán.}

fin de a época colonial. El Yucatán del siglo XIX y de principios del siglo XX, tampoco se libraría de esta enfermedad endémica. De 1825 a 1830 se reportaron incremento en el número de casos de Yucatán y para 1858 se consideraba endémicamente importante (9) e inclusive en 1891 se describe que las personas que fallecieron en Veracruz "eran todas o casi todas de la Habana o de Yucatán, en donde reinaba entonces la epidemia" (10). En 1905 y 1906, y posteriormente en 1911, hubo nuevos brotes epidémicos de fiebre amarilla en Yucatán, principalmente en Mérida.

\section{LAS BASES CIENTÍFICAS DEL CONTROL DE LA FIEBRE AMARILLA.}

Todavía a principios del siglo XX, era frecuente ver ondear banderas amarillas en las azoteas de las casas de Veracruz y Mérida. Ellas traían un mensaje implícito, que comprendía toda la población, incluso los niños todavía analfabetas. Era una señal de cuarentena que se emitía para avisar a la población que no se acercara a esos sitios ya devastados por la fiebre amarilla, que entre la gente era bien identificada como el "vómito negro". Esa misma bandera sería posteriormente el símbolo para señalar el trabajo de las brigadas sanitarias, que de casa en casa, realizaban para erradicar el Aëdes aegypti.

Es indiscutible los trabajos del Dr. Finlay fueron los que dieron origen a las bases científicas que permitieron conocer el mecanismo de transmisión del virus de la fiebre amarilla y el control de su vector. Carlos J. Finlay y Barrés nació en Puerto Príncipe (hoy Camagüey), Cuba, en diciembre de 1833. Su padre Edward Finlay fue un médico escocés, que emigró de Inglaterra alrededor de 1812, para unirse a una fuerza expedicionaria británica, cuya objetivo era colaborar con Simón Bolívar en la guerra de independencia de Venezuela. El buque en el que iba naufragó y el Dr. Edward Finlay terminó en Puerto España, Trinidad, en donde conoció a Eliza de Barrés con quien casó. A los pocos años se mudaron a Puerto Príncipe, lugar en donde nació Carlos Finlay. Carlos Finlay y Barrés realizó estudios de medicina en Rouen y Filadelfia. En 1857 se estableció en la
Habana, Cuba y aunque su especialización era la oftalmología, sus dotes intelectuales le permitieron incursionar en varios campos de la Medicina, además de ser un estudios de la filología, cosmología y de las matemáticas avanzadas (11).

Curiosamente, durante varios años Finaly atribuyó la alta incidencia de fiebre amarilla en la Habana a la "alcalinidad del aire" y en numerosos trabajos presentados en la Real Academia de Ciencias Médicas, Físicas y Naturales de la Habana y en la Sociedad de Estudios Clínicos, trató de demostrar su teoría y buscar el respaldo a la misma de sus colegas. Sin embargo esta idea la abandonó con el paso de los años (12).

En febrero de 1881, como delegado de Cuba ante la Conferencia Sanitaria Internacional, celebrada en Washington D.C., disertó sobre la fiebre amarilla y expresó que uno de los requisitos para su diseminación era "la presencia de un agente cuya existencia sea completamente independiente de la enfermedad y del enfermo" (12). Sin duda ya tenía la primera pista del papel de los mosquitos en la transmisión de esta enfermedad.

Posterior a esta fecha, Finlay comenzó a experimentar con seres humanos, exponiendo a personas susceptibles a la picadura del mosquito que habían picado a pacientes con fiebre amarilla. Sus resultados fueron presentados, en agosto de 1881, a la Academia de Ciencias, en donde se señalaba que la fiebre amarilla se trasmitía por un mosquito culex $\mathrm{o}$ stegomya (13), nombres como era referido el Aëdes aegypti. Sin embargo, no fue hasta 1900, cuando Walter Reed publica su trabajo sobre la trasmisión de la fiebre amarilla, que se comprobó la teoría de Carlos. J. Finlay (14).

El impacto de la fiebre amarilla en Cuba, era de tal magnitud, que durante la $17^{\circ}$ reunión anual de la Asociación Americana de Salud Pública, realizada en Brooklyn, Nueva York, en 1899, en la que asistieron profesionales de Estados Unidos de Norteamérica, Canadá y México, el Dr. Benjamín Lee, presentó una demanda para anexar a Cuba y poder realizar campañas de sanidad en la isla (15). Posterior a la guerra hispano-americana, ocurrida en 1898, la

Vol.15/No.4/Octubre-Diciembre, 2004 


\section{RA Góngora-Biachi.}

petición del Dr. Lee se había cumplido. Estados Unidos tenía el control político de Cuba, lo que permitió la intervención del ejército de ese país en la investigación de la causa de la fiebre amarilla, a través de la "Comisión de la Fiebre Amarilla". Esta comisión fue la que autorizó al Mayor Walter Reed realizar los experimentos en seres humanos que confirmarían la hipótesis Carlos J. Finlay y Barrés (15).

\section{EN BUSCA DE LA ERRADICACIÓN DEL Ä̈DES AEGYPTI.}

A partir de entonces, las campañas se encaminaron a erradicar el vector de la fiebre amarilla. El éxito obtenido en Cuba se traslado a la zona de la construcción del canal de Panamá, en donde, junto con el paludismo, la fiebre amarilla había cobrado una cuota de 20,000 defunciones (15).

En 1905 y 1906 hubo un brote de fiebre amarilla en Mérida, Yucatán, el que afortunadamente fue autolimitado. En agosto de 1911, esta enfermedad hizo su aparición de nueva cuenta en esta ciudad. La epidemia fue de menor impacto que el brote de 19051906: en seis meses se habían registrado 65 casos y 29 defunciones. Sin embargo, llamaba la atención el fracaso de las medidas tomadas anteriormente al brote, en esta ciudad. El titular del Consejo Superior de Salubridad, el Dr. Eduardo Liceaga -médico que en septiembre de 1903 inició en Veracruz la campaña contra los mosquitos-, en un reporte fechado el 23 de febrero de 1912, propone la hipótesis de un reservorio no humano aún no considerado (2): "Se ha pensado que supuesto que los procedimientos que han sido eficaces, no solamente en países diferentes al nuestro, sino en todos los lugares del litoral del Golfo, en donde era endémica la fiebre amarilla y muy especialmente en Veracruz, foco secular de la enfermedad, no han servido ahora, es indispensable reflexionar que hay algunas circunstancias especiales que han hecho reaparecer la epidemia en Mérida".

La epidemia se limitó antes que la guerra de la Revolución Mexicana. El 19 de enero de 1921, el presidente Álvaro Obregón, firmó un acuerdo para intensificar la campaña contra la fiebre amarilla y el decreto estableció una comisión especial "con el objeto de combatir la enfermedad por cuantos medios sea posible, hasta su completa extinción en el país y colaborar en el mismo sentido con otros países, cuando para ello se requiera" (16). La comisión estaba integrada por médicos mexicanos e incorporó a científicos de la Oficina de Higiene Internacional de la Fundación Rockefeller. El país fue dividido en siete zonas de riesgo, incluyendo a la Península de Yucatán, que correspondía a la zona 3.

El Dr. Diego Hernández Fajardo era el Delegado Jefe de la campaña en Mérida, cargo que ocupó hasta abril de 1923, cuando partió a Nueva York para hacer estudios en el Instituto Rockefeller, en el laboratorio del Dr. Hideyo Noguchi.

El Dr. Diego Hernández Fajardo, junto con sus colegas Hircano Ayuso O'Horibe, Efraín Gutiérrez Rivas y Mario Villamil, desde 1906 y bajo la tutela del Dr. Haral Sidelin, distinguido sabio danés, habían iniciado en Yucatán el estudio formal de la fiebre amarilla, en los laboratorios del Hospital "Dr. Agustín 0’Horán”, en la ciudad de Mérida. Según describe el Dr. Pedro Cámara Millán (17): "Se trabajaba día y noche, las autopsias de cadáveres de fiebre amarilla eran muchas y el material procedente de ellas que había que estudiar era abundante; cantidades de preparaciones microscópicas de sangre y de tejidos había que examinar. El objetivo era descubrir el agente invisible que producía el mal...". Sin embargo, en 1910, el Dr. Seidelin renunció al Hospital sin haber logrado su objetivo en torno a la fiebre amarilla.

Ya desde 1918, el Dr. Hideyo Noguchi se dedicaba con vehemencia y asiduidad al estudio de la fiebre amarilla. En diciembre de 1919, llegó a Mérida, Yucatán, enviado por el Instituto Rockefeller para continuar los estudios sobre fiebre amarilla. Aún faltaba por descubrir el agente causal del mal. Pero la epidemia en Mérida ya estaba declinando, los casos eran ya escasos y el material clínico, en consecuencia, lo era también. La estancia de Noguchi en Mérida ya careció de interés, lo que hizo que su permanencia en el estado de Yucatán sea apenas de algunas semanas, dedicadas a la investigación intensa. Noguchi promovió buenos amigos y discípulos, incluso, como el caso del Dr. Hernández Fajardo, los invitó a

\section{Revista Biomédica}




\section{Erradicación de la fiebre amarilla en Yucatán.}

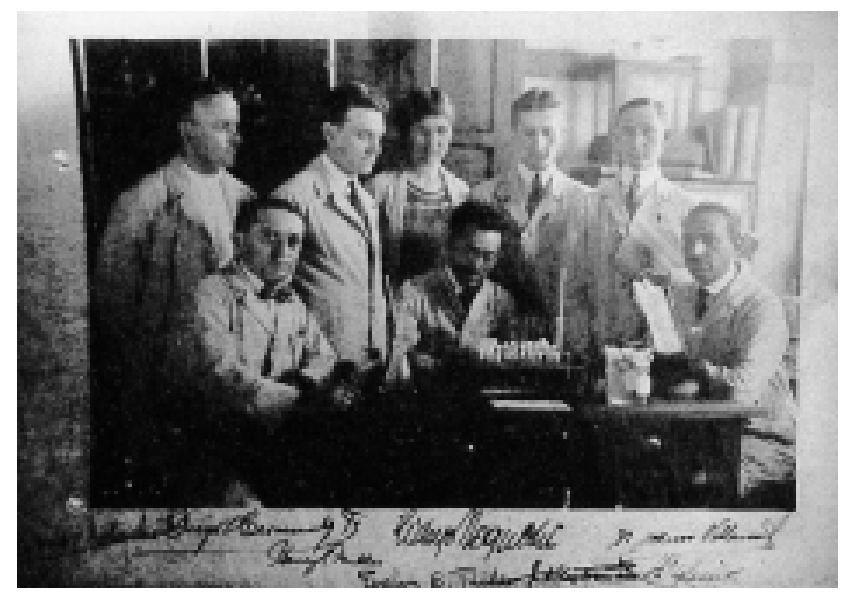

Figura 1.- Gráfica tomada en el Instituto Rockefeller de Nueva York en el año de 1922. De izquierda a derecha aparecen los médicos siguientes: Dieterick H. Dieterick, J. Muller, Ellis B Tilden, (Secretaria del Dr. Noguchi), B. Royers y Mario Villamil M. -Primera fila: Diego Hernández Fajardo, Hideyo Noguchi y Alfredo Iglesias, de Veracruz.

participar con él en su laboratorio de Nueva York (figura 1).

En el último informe que firma como Delegado Jefe de la campaña contra la fiebre amarilla, el 14 de abril de 1923 (2), el Dr. Diego Hernández Fajardo señala que su equipo lo integraban 37 empleados: un jefe de servicio, un secretario, un escribiente, un inspector general, un revisor general, 15 agentes y 17 ayudantes de agente o petroleros. La ciudad de Mérida la había dividido en 13 distritos, en los que trabajaban los agentes diariamente, de las siete a once de la mañana y de la una a las cinco de la tarde, cada uno con su petrolero. La ciudad tenía cerca de 16,000 casas y diariamente se visitaban 2,000 de ellas, por lo que estimaba que cada ocho días de trabajo se podía visitar la ciudad entera.

Y así la inspección continuaba semana tras semana. Se revisaban los depósitos de agua de las casas, los sumideros (fosas sépticas), los aljibes de agua lluvia, las piletas, las tinajas, las ollas y los floreros. Narra en su informe que un problema especial lo constituyen los depósitos de agua con lejía, utilizada para el lavado de ropa y que era un excelente medio de cultivo del mosquito. Otro problema lo fueron los aljibes de agua lluvia, única fuente de esa época de

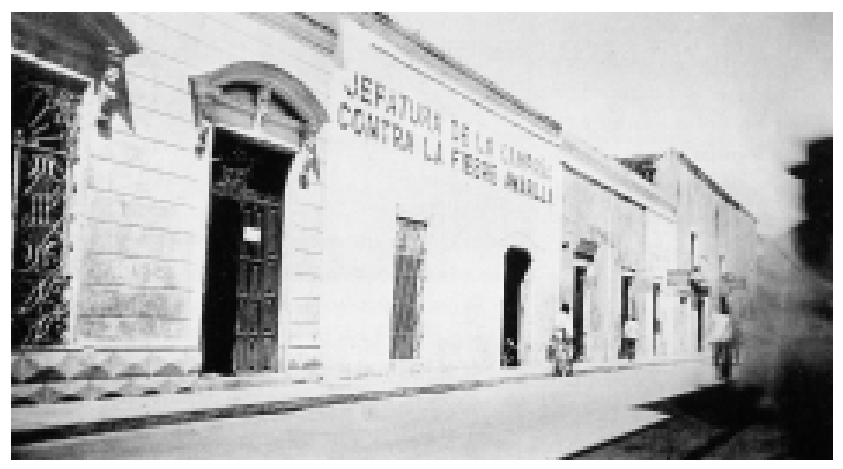

Figura 2.- Oficina de Jefatura de la Campaña Contra la Fiebre Amarilla en Mérida, Yucatán (1922). Archivo de Concentración e Histórico de la Secretaría de Salud, fondo SP/Spid., caja 38, expediente 6 .

agua para consumo humano. Era imposible realizar la petrolización en estos depósitos. Sin embargo la solución llegó pronto: peces larvacidas, como la mojarra (que fue la que se usó preferentemente en Mérida), el chalaco, la lisa, el robalito plateado y la gambusía.

En esta campaña se petrolizaron alrededor de 12,000 sumideros y se reporto el uso de 24,192 litros de petróleo. El informe se acompaña de una colección de fotos, parte de ellas presentadas en este escrito (figuras 2 a 8, fuente: Archivo de Concentración e Histórico de la Secretaría de Salud, fondo SP/ Epidemiología, caja 38, expediente 6), en donde se muestra al equipo y las labores que desarrollaban. El control del Aëdes aegypti y la erradicación de la fiebre amarilla en Mérida, Yucatán se habían logrado.

\section{COLOFÓN.}

Del 15 al 21 de octubre de 1924, en la ciudad de México se realizó una reunión de delegados de la campaña contra la fiebre amarilla y se declaró erradicada en la república mexicana. El 6 de agosto de 1963, las autoridades mexicanas entregaron a las autoridades sanitarias de Estados Unidos, dentro de un cubo de plástico, la última pareja de Aëdes aegypti capturados en México. El primero de septiembre de 1963, el Presidente Adolfo López Mateos informó al pueblo, a través de las Cámaras legislativas, que México había quedado libre del vector de la fiebre amarilla urbana. Sin embargo, en 1969, y transmitiendo 


\section{RA Góngora-Biachi.}

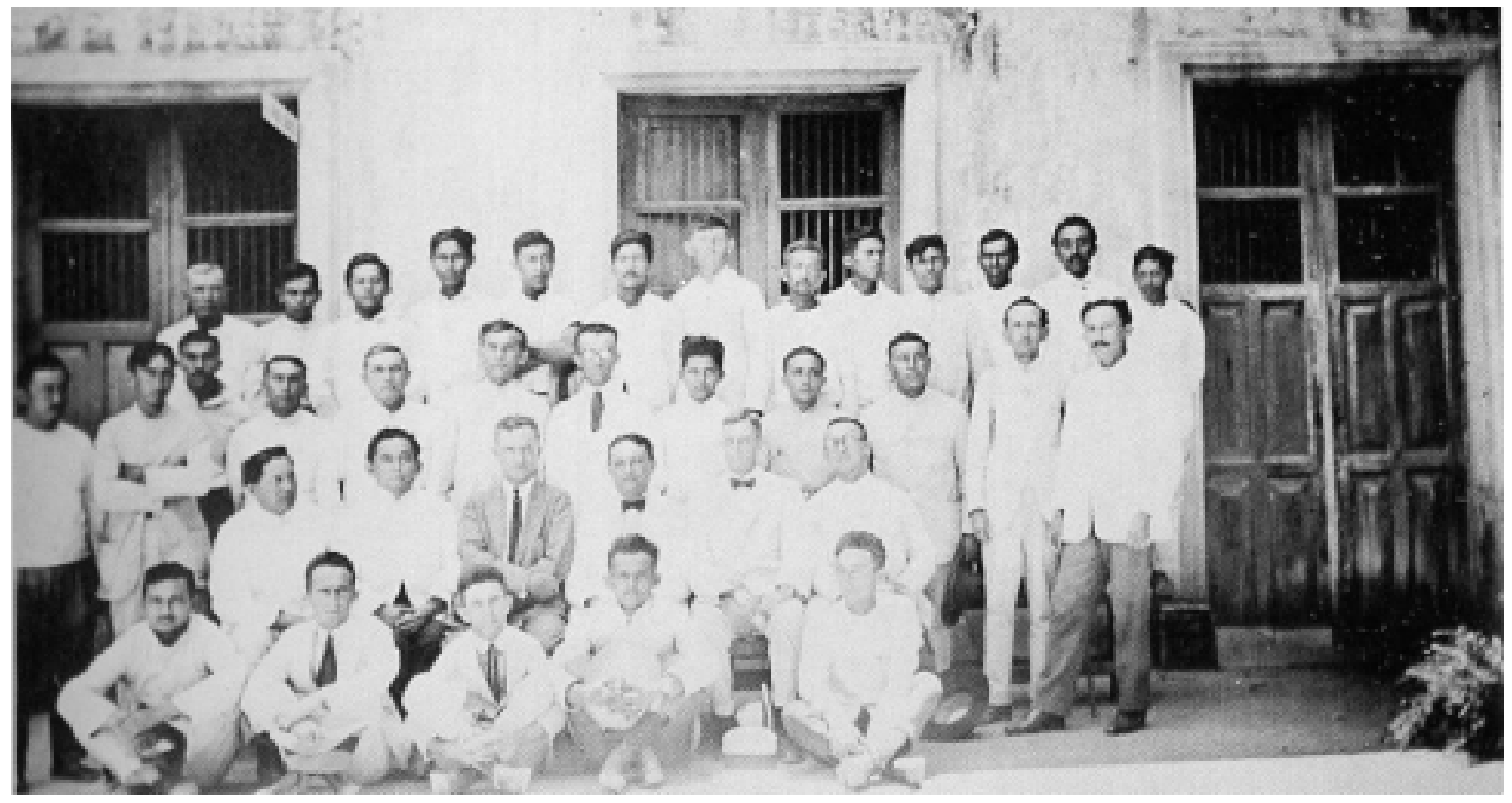

Figura 3.- Personal y jefes del Servicio, adscritos a la Campaña Contra la Fiebre Amarilla en Mérida, Yucatán (1922).

otro virus, el del dengue, reapareció este vector, mostrando que quizá la historia de la fiebre amarilla en México aún puede continuar.

\section{REFERENCIAS.}

1.- Peters CJ. Infections caused by arthropod- and rodent borne viruses. En Fauci AS, Braunwald E, Isselbacher KJ,
Wilson JD, Martin JB, Kasper DL, Hauser SL, Longo DL, eds. Harison's Principles of Internal Medicine. $14^{\text {th }}$ edition. New York: McGraw-Hill; 1998. p. 1132-46.

2.- Ortiz M. Fiebre Amarilla. En: Sepúlveda-Amor J, ed., Devenir de la salud pública en México durante el siglo XX. México: Instituto Nacional de Salud Pública; 2000. p. 55-71.

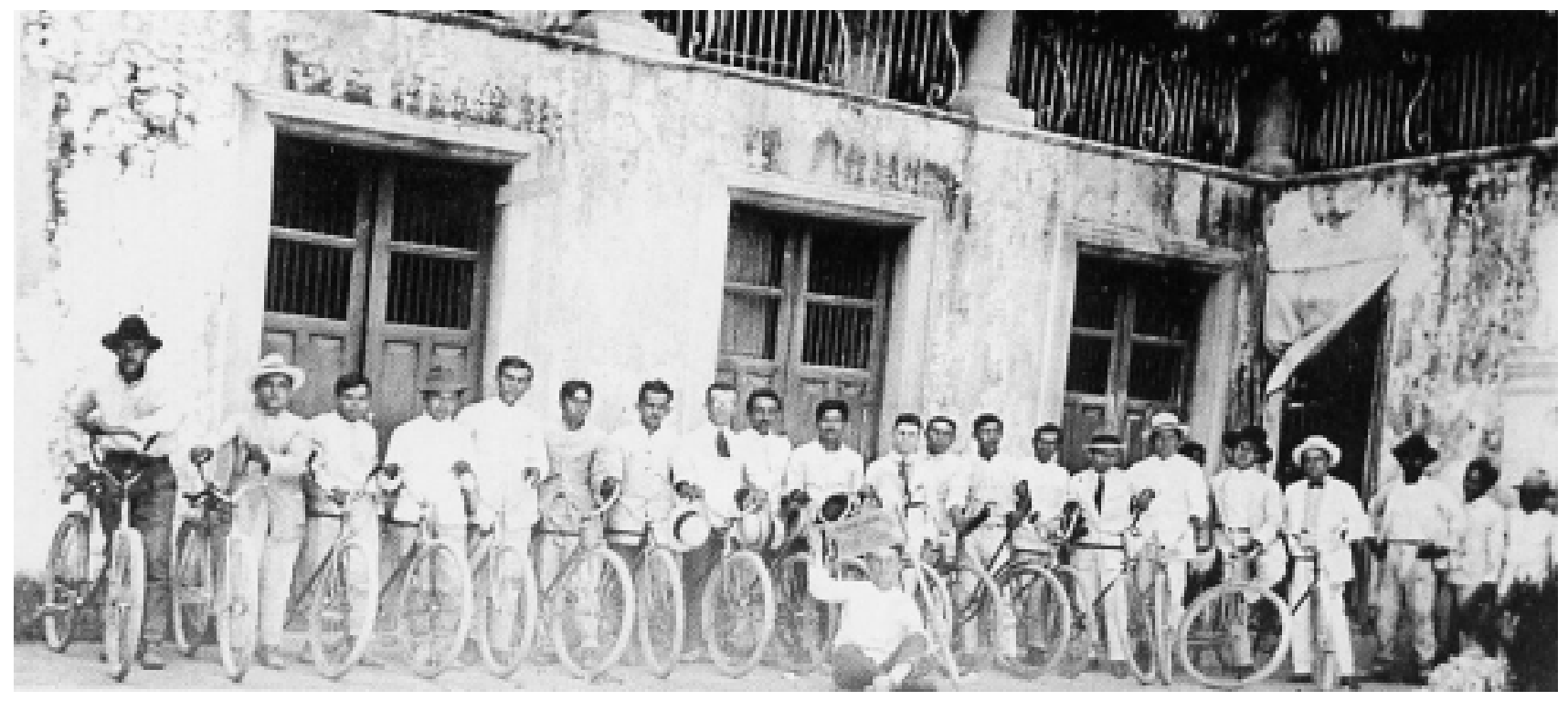

\section{Revista Biomédica}

Figura 4.- Brigada bicicletera contra la fiebre amarilla. 


\section{Erradicación de la fiebre amarilla en Yucatán.}

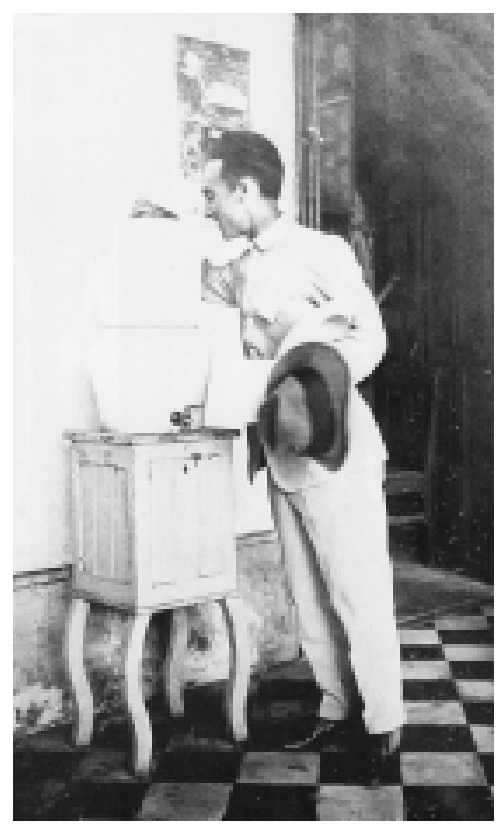

Figura 5.- Agente de visita domiciliaria revisando un depósito de agua con su linterna eléctrica.

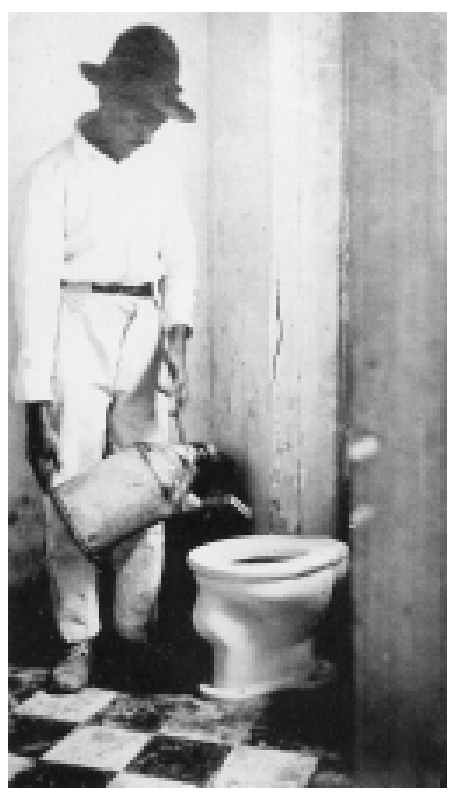

Figura 6.- Ayudante, en visita domiciliaria, petrolizando un sumidero por conducto del inodoro.

3.- Sanfilippo J. El espectacular y terrible "vómito negro". Médico Moderno 1987; 26(2):66-85.

4.- Góngora-Biachi RA. La Fiebre Amarilla en Yucatán durante las épocas precolombina y colonial. Rev Biomed 2000; 11:3017.

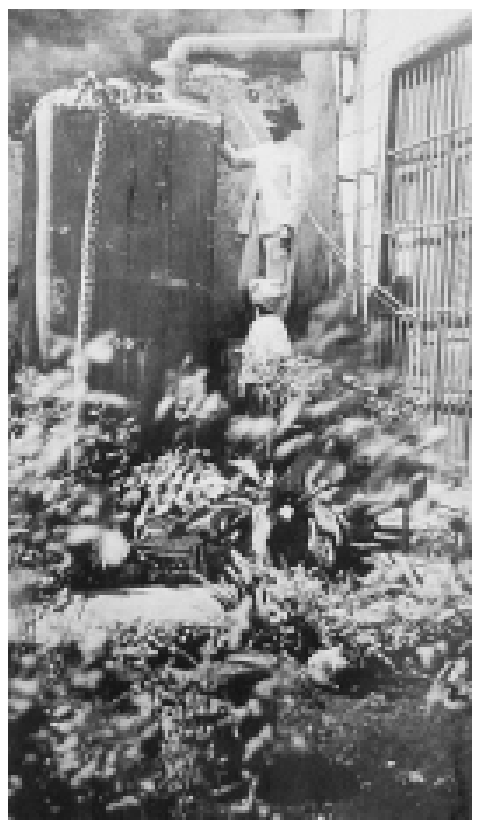

Figura 7.- Agente y ayudante en visita domiciliaria, revisando un depósito que se destina para recoger agua de lluvia.

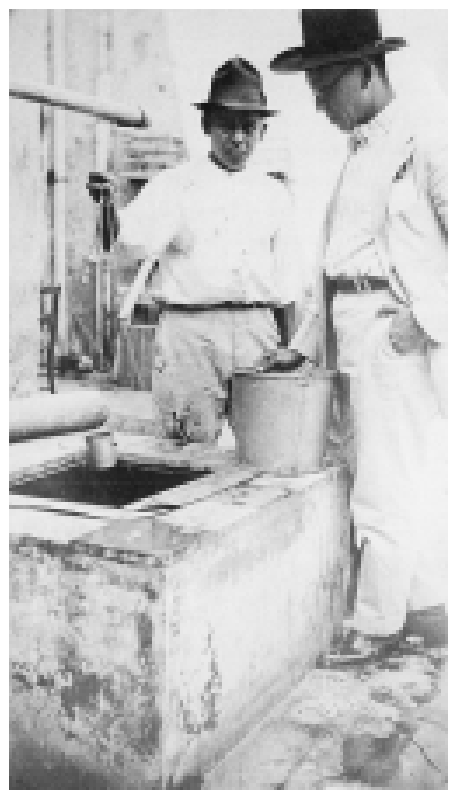

Figura 8.- Inspector General y Pescador, depositando una mojarra en un aljibe (cisterna).

5.- Barrera-Vásquez A, Rendón S. El libro de los libros de Chilam Balam. México: Fondo de la Cultura Económica; 1948. p. 21-43.

6.- De Landa D. Relación de las Cosas de Yucatán. México: Editorial Porrúa; 1978. p. 19-20. 


\section{RA Góngora-Biachi.}

7.- Quesada S. Epidemias, plagas y hambres en Yucatán, México (1520-1700). Rev Biomed 1995; 6:238-42.

8.- López Cogolludo D. Historia de Yucatán. 5 a . Ed. Campeche: H. Ayuntamiento de Campeche; 1996. p. 368-393.

9.- Del Río y Bausa N. La epidemia dela fiebre amarilla. Salud Pública Mex 1995; 37:257-63.

10.- Torres-Muñoz a. La fiebre amarilla en México. Erradicación del Aëdes aegypti. Salud Pública Mex 1995; 37 (suppl):S103S118.

11.- Leonard J. La vida de Carlos Finlay y la derrota de labandera amarilla. Bol Of Sanit Panam 1990; 108: 229-44.

12.- Finaly C. Obras completas. La Habana: Academia de Ciencias de Cuba; 1965. Vol. 1: 197-8.

13.- Finlay C. El mosquito hipotéticamente considerado como agente de transmisión de la fiebre amarilla. Salud Pública Mex 1992; 34:474-83.

14.- Reed W, Carroll J, Agramonte A, Lazear J. The etiology of yellow fever. A preliminary note. Philadelphia Med J 1900; 6:790-6.

15.- Güereña-Burgueño F. The centenal of the Yellow Fever Comisión and the use of informed consent in medical research. Salud Publica Mex 2002; 44:140-4.

16.- Archivo Histórico de la Secretaría de Salud. Copia del acuerdo Presidencial que crea la "Comisión Especial para la campaña contra la Fiebre amarilla". Fondo: Salubridad Pública. Sección: Servicio Jurídico. Volumen 2; Expediente 7. Fechas 1921-1925.

17.- Cámara-Millan P. El Dr. Hideyo Noguchi en Yucatán. Rev Biomed 2000; 11:207-12.

\section{Revista Biomédica}

